\title{
Health Care Professionals and Family Perspectives of Youth's Trauma: Suggestions for Coaching and Self-Leadership
}

\author{
Karien Jooste ${ }^{* 1}$ and Jeanette Maritz ${ }^{2}$ \\ ${ }^{I}$ School of Nursing, University of the Western Cape, Bellville, Cape Town, 7353, South Africa \\ ${ }^{2}$ Department of Health Studies, University of South Africa, Pretoria, South Africa
}

\begin{abstract}
Family forms the first and most important social institution in every society. Although traumatised families may be the root of much personal and social turmoil, a healthy community and family is the most vital way to deal with social change and challenges. In the light of increasing violence and trauma in South Africa, youths adverse exposures to violence and trauma have been identified as a distressing health care problem globally and for our communities and families at large. This study sought to explore and describe community and family perspectives of youth's trauma in order to propose a holistic support approach. A qualitative approach was followed and participants (health care professionals and parents) were purposefully selected. Data were gathered through interviews, a focus group and field notes. Data were analysed thematically. Health care professionals and parents shared similar experiences and concerns relating to their perceptions of youths' experiences of trauma. Parents however had a more negative regard of the youth and their capabilities to deal with trauma. The trauma experience was seldom contained to the individual but had a traumatising ripple effect on the parents, and community. This often left the entire system feeling helpless and depleted of resources to cope.
\end{abstract}

Keywords: Coaching, health care professionals, parents, primary health care, self-leadership, trauma.

\section{INTRODUCTION}

Many children, adolescents, and their families are exposed to trauma that raise the concern about the impact of traumatic exposure on children and how these children and their families can best be helped [1]. Violence and other traumatic events are frequent in developing countries. Trauma refers to an event in which one's physical integrity is threatened and causes horror, terror or helplessness [2]. Violence and unintentional injury make up one of the four major health burdens in South Africa, along with HIV and tuberculosis, chronic illness and mental health, and maternal, neonatal and child health [3]. These authors [3] predict that over the course of a lifetime, up to $75 \%$ of South Africans will experience at least one traumatic event. Their study found that violence in South Africa is notable for its distinct gender, age and socio-economic features. The exposure of girls and women to interpersonal violence is widespread, with a large proportion of traumatic events linked to acts of sexual violence, which are often under-reported. The rate of female homicide involving intimate partners is six times the global rate, whereas the exposure of men to violence, especially severe and homicidal forms of aggression, is also of considerable concern, with male homicide in South Africa being eight times the global indicator. Age-related vulnerability is reflected in the concentration of violent death of young men and children. The highest rate of homicide is

*Address correspondence to this author at the School of Nursing, Private Bag x17 Bellville University of the Western Cape, Bellville, Cape Town, 7353, South Africa; Tel: 27(21) 9592274; E-mail: kjooste@uwc.ac.za among men aged $15-29$ years (184 per 100 000). In South Africa there are currently in 2014, 19.5 million young people aged 15-34 years. In 2014, of the 4.6 million youth residing in Gauteng, in South Africa 679000 (14.9\%) lived in households in which no one is employed [4].

The social dynamics that support violence are widespread poverty, unemployment, and income inequality; patriarchal notions of masculinity that values toughness, risk-taking, and defence of honour; exposure to abuse in childhood and weak parenting; access to firearms; widespread alcohol misuse; and weaknesses in the mechanisms of law enforcement [5]. Youths adverse exposures to violence and trauma have been identified as a distressing health care problem globally and for our communities and families at large [6].

In addition, many South African communities (a geographic space within which residents share values, norms and activities that create a sense of community) families (a group of people dwelling together) and individuals (in this case youth) have endured severe deprivation and political oppression [7]. Depending on their responses to trauma people may experience a disruption of their sense of connection between past, present and future. This may create stress on the extended system of support such as the community and families. Left unattended a myriad of dysfunctions may follow, such as further violence and tension, addiction [8], psychiatric disorders such as depression, suicide, traumatic stress and an increase in risktaking behaviours that may lead to HIV/AIDS [7].

Family forms the first and most important social institution in every society [8]. Although traumatised 
families may be the root of much personal and social turmoil, a healthy community and family is the most vital way to deal with social change and challenges. Communities and families have through the ages shown themselves to be resilient and to survive trauma, often with an increased strength and resources [7]. Culturally responsive efforts to engage communities and families in treatment are however needed.

\section{BACKGROUND AND SIGNIFICANCE}

A number of psychosocial support interventions programmes and community involvement actions have focused on supporting both parents and youth after traumatic events. Authors [9] descibe their university- community partnership programme which sought to heal historical trauma, strengthen positive parenting practices and social skills, reconnecting to traditional cultural knowledge and improving parent-child relationships/communication. They report that the programme had mixed results.

Therapeutic mentoring [10] has shown promising results as a treatment intervention for traumatised youth. The role of a more therapeutic approach to mentoring, which involves mentors with a background in a helping profession who are paid for their service and who receive extensive and ongoing training and supervision may however be out of reach for most youth in South Africa. Peer mentoring and coaching models have shown to have value as a social support action. The word peer implies that the support is designed and delivered by people who have both experienced and recovered from trauma. In this context the term mentoring and coaching refers to a one-on-one relationship in which a peer leader with more recovery experience than the person served encourages, motivates, and supports a peer who is seeking to establish or enhance their coping mecansism or recovery [11]. The types of support that such programmes facilitated included emotional, informational, instrumental and affiliational.

It is stated [12] that the general goal of coaching is to improve planned goal-orientated and ultimately successful behaviour. Self-coaching interventions help the individual to construct a positive image of self [12], and is more effective than coaching from a peer or an external coach [13] and provide individuals with an edge over their un-coached peers [14] when considering their own self-leadership capabilities. Self-coaching harnesses intrinsic and extrinsic resources to become compassionate witnesses, thereby changing the behaviour and reactions of families and communities to violence and trauma [15].

One of the primary aims of self-leadership is to achieve higher performance and effectiveness through behavioral and cognitive strategies that individuals use to influence themselves [16]. It is a comprehensive view of self-influence that considers behavior to be a result of factors both internal and external to the individual. Although many people appear to recover from trauma without intervention, many do not, and they require continual attention to their distress and dysfunction [17]. Self-leadership thus has potential as it is "the process" of influencing oneself to establish the selfdirection and self-motivation needed to continue to attain certain goals [18]. Many studies have been conducted on traumatized youth, however little is known about selfleadership of the youth. This study was conducted as it was unclear what the experiences of parents and health care professionals were on the role of self-leadership among traumatized youth.

This study formed part of a larger project into youths' experience of trauma. The study took place in the greater Johannesburg metropolitan and investigated youth, parents (as family) and health care professionals (HCP) (as community) perspectives on youth experiencing traumatic events. Parents and HCP were included in this study with the hope of gaining a wider and richer perspective of the experiences on the wider community surrounding youth who have experienced trauma.

Johannesburg, with a population of 3.2 million spread across one million households, is characterized by its youthful residents, with 42 percentage of the population under the age of 23. The number of households is increasing, placing huge demands on the City's economic and social infrastructure [4]. Youths' experience of trauma has previously been reported on. The youth expressed their experience of the traumatic events as life changing, and as a catalyst for profound awakening and personal transformation. Although the experience was negative for most, two participants related positive outcomes. The most significant finding was that self-support manifested through self-leadership and self-coaching. This was however a process of adaptation. Participants used four main selfcoaching strategies namely cognitive strategies, emotional and spiritual care and social support [19].

The aim of this report is to reflect on the understanding gained from HCP (nurses) and parents' experiences of youth's trauma and also to identify interventions that may be most useful to support traumatised youth.

\section{PARADIGMATIC FRAMEWORK}

The philosophy of Appreciative Inquiry (AI) was used in this study as it falls within the ambit of social constructionism. Social constructionism represents an approach to human science inquiry and practice, characterised by a relational focus, emphasising the notion that the world that people create in the process of social exchange constitutes their realities [20]. Thus human realities, such as self-coaching and self-leadership, are seen as social constructs. Assumptions are basic principles that are taken for granted or accepted without questioning [21]. Authors [22] believe that being able to recognize these assumptions is regarded as strength and lend rigour to the study.

This study supported [23] the principles and assumptions of AI that:

- The potential for growth is an inherent part of the human condition [24].

- In every society, organisation, group or individual, something works. It is believed that with parents, selfcoaching and self-leadership (the something) is already practised. 
- What we focus on becomes our realities. If the researcher enquired about the self-coaching and selfleadership of the parent with their traumatized child, the parent would become more aware of these actions and focus more on it.

- Reality is created in the moment and there are multiple realities. Our reality on self-leadership is created when we practise self-coaching and selfleadership.

- $\quad$ The act of asking questions of individuals influences them in some way. The researcher asked questions about self-coaching and self-leadership and influenced the parent in some way.

- $\quad$ People have more confidence and comfort to journey to the future (the unknown) when they carry forward parts of the past (the known). Parents would have more confidence with their own actions in their future practices when they carry parts of their past practices forward.

- It is important to value differences. The language we use creates our realities.

We add to this the Linking Human Systems (LINC) Community Resilience model [25]. The model assumes that with the appropriate support and encouragement, individual and collective strength can be harnessed in order to transcend hardship, trauma or loss. Families and communities are thus active agents of change and support [7].

\section{METHODS}

In this study a qualitative, descriptive, exploratory and contextual design was used [26]. Qualitative research was viewed as appropriate for investigating the phenomena of traumatised youth in the clinical settings and the community that brought insight into supporting traumatised youth in the community. Authors [27] suggest that quantitative methods, used alone, cannot fully capture the full nature of human suffering, because they cannot encompass the richness and nuance of its meaning. Quantitative approaches can miss the complexity of traumatic responses. Free-standing qualitative programmes of study could suggest directions for quantitative work, enrich the understanding of quantitative findings, and explore phenomena which cannot feasibly be well-studied quantitatively [27]. The design incorporated the philosophy of the Appreciative Inquiry paradigm.

\section{Sample}

A total of 25 participants were involved during July 2012. Nine participants were parents (seven mothers and two were fathers). Parents were selected on the bases of having a traumatised child (youth) that attended a primary health care clinic in Region B of Gauteng, Johannesburg Metropolitan. Sixteen HCP (nurses at primary health care facilities who dealt with traumatised youth) were also included. Purposive sampling was employed whereby participants complied with the inclusion criteria were interviewed until saturation occurred and the information began to repeat itself [28].

The researchers wanted to explore how HCPs and parents experience the traumatized youth member in the
Johannesburg community. Experiences were viewed as the knowledge or practical wisdom gained from what one has observed or encountered, or undergone. Secondly, it was investigated how the traumatized youth member should be supported to lead him/herself after being traumatized. Data were collected through in-depth individual interviews with parents and HCP that lasted between 20-32 minutes [26] as well as one focus group with nurses lasting 95 minutes [29]. Individual interviews and a focus group were combined in order to enhance data richness [30].

This method allowed for more flexibility for both the researcher and the participant, since the framing of the questions could be adapted to cater for the participant's understanding and for the researcher to gain the relevant information from the participant. The questions were openended and the participants were able to share more closely in the direction that the interview took and even introduced issues that the researcher had not thought about [31].

The research questions were posed as:

- What do you find to be effective during self-coaching and self-leadership with the traumatized child?

- What would you like to include in self-coaching and the self-leadership of the child?

The researcher therefore prepared for the interviews by deciding on the questions that she would ask [31]. Time was allowed for building rapport with the participants prior to the formal interviews and focus group. The focus groups allowed for frank discussions but also provided a sense of universalism in that the participants did not feel alone in their experiences. Data were collected in Primary Health Care Clinic's in Region B Gauteng, Johannesburg. In addition a field diary [22] was kept in order to jot down insights as they occurred as well as personal responses of the researchers to the events and experiences of the participants.

A suitable venue was chosen where the participants were afforded comfort, privacy, and a non-threatening environment without interruption. The researcher ensured that the tape recorder equipment used to record the interviews was available and in working condition and of a high quality. A counsellor was available if a parent needed support during or after the interviews. Two pilot individual interviews were conducted to ensure that the research questions served the purpose of the study.

\section{Data Analysis}

Each group of participants' data were analysed as an entity (parents and healthcare workers), before being combined for a holistic picture. Data were analysed using NVivo 10 software. The computerised program proved useful for storing and organising interviews, and notes as well as quantifying the number of sources, references and coverage of codes. The software also served as an audit trail. As computers do not think on one's behalf, we used the data analysis spiral [26].

After the data were organised into computer files and files were converted into text units, transcripts were read in their entirety several times to establish a sense of the whole before breaking it into parts. Memos (short phrases or ideas) 
were written in the margins. Initial codes and categories were formed and later refined. We looked for multiple forms of evidence to support each. These were aggregated to form a major theme.

\section{Measures of Trustworthiness}

Strategies employed to ensure the quality of data included the following measures of trustworthiness [32]: credibility (triangulation and reflectivity); applicability (rich descriptions and purposeful sampling); dependability (code, recode procedures); confirmability (triangulation and reflectivity); and authenticity (fairness, awareness, understanding, action and empowerment) [33].

\section{Ethical Considerations}

The following ethical considerations [31] were taken into account: consent to conduct research was requested and granted by the Department of Health in Johannesburg. Informed written consent was obtained from all participants, also providing a letter communicating the necessary information pertaining to the project. Although the researchers could not offer participants of the focus group internal confidentiality because it was outside their control, external confidentiality [34] was maintained through the anonymity of responses. Participation was voluntary and no form of compensation was awarded to the participants.

\section{RESULTS}

Health care professionals (HCP) and parents shared similar experiences and concerns relating to their perceptions of youths' experiences of trauma. Parents however had a more negative regard of the youth and their capabilities to deal with trauma. HCP mentioned assault, rape, poverty and teenage pregnancy as the main types of trauma that youth dealt with. Parents related different types of trauma that the youth were exposed to. This included robbery, rape and sexual abuse, substance abuse, unemployment, poverty, parents' divorce or death, teenage pregnancy, HIV and witnessing of trauma. The trauma experience was seldom contained to the individual but had a traumatic ripple effect on the parents, and community. This often left the entire system feeling helpless and depleted of resources to cope.

Four superordinate themes were identified. These were divided in subthemes. The four superordinate themes were 1) The effects of trauma on the caring system; 2) Perception of the youth; 3) Lack of resources in coping and 4) Culminating effects of trauma. Suggestions for a holistic self-coaching and leadership approach are then put forth.

\section{The Effects of Trauma on the Caring System}

According to literature [35] a system of care is a spectrum of effective, community-based services and supports for youth with or at risk for mental health or other challenges and their families, that is organised into a coordinated network, builds meaningful partnerships with families and youth, and addresses their cultural and linguistic needs, in order to help them to function better at home, in school, in the community, and throughout life.

Secondary trauma resulted in emotional pain. Both the parents and HCPs acutely felt the youth's pain after a traumatic event. HCP's mentioned: "it's very painful" and "it's not nice". This often left them with secondary trauma but also evoked empathy: "I felt so traumatised also because I could cry with her and I felt that I put myself in the shoes of her mother being my daughter and having to go through that". Parents were often traumatised by their child's pain: "I didn't sleep those first months it was so painful..." A mother mentioned that it is: "a strain, it is stressful ... just hectic".

It is stated [36] that those in close contact with trauma survivors are themselves at risk for (secondary) trauma. Secondary trauma involves the transfer and acquisition of

Table 1. Themes and categories.

\begin{tabular}{|c|c|}
\hline Health Care Worker as Community & Parents as Family \\
\hline \multicolumn{2}{|l|}{ Effects of trauma on the caring system } \\
\hline \multicolumn{2}{|l|}{ Perception of youth } \\
\hline $\begin{array}{l}\text { - Positive regard but in pain } \\
\text { - In need of direction and support }\end{array}$ & - Disrespectful and out of control \\
\hline $\begin{array}{l}\text { - } \quad \text { Professional resources } \\
\text { - } \quad \text { Community } \\
\text { - } \quad \text { Lack of involvement from parents }\end{array}$ & $\begin{array}{l}\text { - Lack of awareness of services } \\
\text { - The lack and influence of role models }\end{array}$ \\
\hline \multicolumn{2}{|l|}{ Culminating effects of trauma } \\
\hline
\end{tabular}


negative affective and dysfunctional cognitive states due to prolonged and extended contact with others, such as family members, who have been traumatized [37].

\section{Perception of the Youth}

Trauma caused youth great distress. Without the necessary coping mechanisms youth would often withdraw. This leads to further isolation and misunderstanding between the youth, HCP and parents. A HCP was able to identify behaviour changes in the youth and attributed these changes to the traumatic event:

"Traumatised youth... you just see a behaviour change, you just see a child that not ah as respectful as he used to be. Em [very short pause] you do see a child is withdrawn, a child someday get out of their age group either [short pause] see themselves as adults some see themselves as insufficient you know and dropping in their self-esteem and then they go into withdrawal [short pause] from their group".

Some of the youth's behaviour changes may be viewed by the uninformed as disrespectful as a HCP explained:

"... so and they get resentment they just get behaviour that's out control and if you try to speak to them they like 'you're not my mother or [short pause] ... jeez it's my time and it's not obeying your time'. The behaviour changes, it changes, even the self-respect of others you see them [short pause] there the normal up to life that respect about themselves. [Short pause]. Ja, then they lose it. No interest in life, something like that, ja".

It is interesting to note that this perception is later echoed in the parents' interviews. Parents often perceived youths' behaviour in a negative light. Without knowledge of trauma, traumatic events or possible reactions to trauma, youth is simply described as having no discipline and being disrespectful in their behaviour or acting out of control. Three parents described the youth's behaviour as:

"I feel that the youth has no discipline"; "I identified that they have no respect when they act out; "she feels guilty but I also see a lack of discipline and respect" but did not link specific behavioural changes to traumatic events. A father mentions " $m y$ child is just out of control".

One HCP might have an explanation in that:

"they [traumatised youth] become detached from their parents".

This might lay the ground for misinterpreting behaviour. Behavioural changes were noted to be pervasive in other contexts such as the church:

"Even in church organizations, yes. You can see something has changed with this child".

Childhood trauma is a high risk factor of depression and personality disorders [38] and may be pervasive into adulthood. Youth may experience feelings of anger, anxiety, depression, social isolation and helplessness as a result of being exposed to violence and trauma [14]. It would be important that the behaviour be linked to adverse traumatic events so as to find appropriate support.

HCPs were able to identify youth's positive mechanism to deal with trauma. This related to the ability to self-coach and -lead. They however needed guidance:

"You cannot do for them. They will not lead, they will only follow. They have to do it themselves". Another echoed this positive sentiment: "they can be able to stand up for themselves".

Another HCP commented that:

"they don't know how to start solving it because you can ask but you are in this situation how do you think you can come out of it? They come up with ideas but then you ask why aren't you doing it? I don't know how, I don't know where to start. You find that they've got the solutions but they don't know how to implement them".

In our report on youths' experiences of trauma we reported that youth were able to mobilise their internal resources. This was however a process of adaptation. The youth in this study used four main self-coaching strategies namely cognitive strategies, emotional and spiritual care and social support [19].

\section{Lack of Environmental Response and Support}

The HCP and parents were acutely aware of the problems in the communities but often found themselves helpless to respond related to inadequate resources and infrastructure. A HCP tried to respond but his responses were often met with lethargy or a lack of resources to sustain projects:

"There are a few programmes in the community that try and help other but none that have made such a big impact. I tried to start a youth programme but the lack of facilities had put it on hold".

Issues of staffing lead to an uneven burden of care and compromises services, and follow up care:
"Staffing becomes a problem sometimes, excuse sometimes, um. [pause] A point to say ok we don't have staff you know with patient quality care, we don't follow them up to an extent where you know where they go because you just see them as they come. You don't come, and then we lose them because you don't have time to do house visits and everything. Even the health promoters they cannot cope with doing. So they follow up on their main issues like TB and everything, but trauma, they just vanish in front of your eyes and you don 't know where they end up".

The overwhelming workload of HCP in Africa is well documented as is the resulting demoralisation of HCP [39]. 
Despite pockets of excellence there is a high level of unmet needs related to follow-up and follow-through care in South Africa family [40]. It was mentioned:

\begin{abstract}
"I think there's a link that short between us and the hospital and us and um maybe other clinics because you know we do things today and when the patient leaves we don't know what happens to the patient the next day. So I think there's a link somewhere that needs to be matched and show that the patient has continued care and is taken care of and everything 's fine with the patient".
\end{abstract}

South Africa as a low- to middle income country is notorious for its resource and capacity limitations. It is reported [41] that marginalisation and competing community priorities influence the implementation of programmes and responsiveness to interventions. Communities face multiple demands related to unemployment, daily living pressures, unemployment and violence. This leads to uneven community engagement pathways. With limited health, social and welfare services available, programmes often fail.

The HCP, the head of one of the clinics mentioned that:

"women are the strength of the community and the ones that take care of families, working and earning the money. Most of the men in the community are unemployed and drink alcohol all day".

This view was supported by our field notes which described what we saw on entering a health care facility. There were a number of youth idling in chairs, young mothers socialising and a number of men smelling of alcohol. Another HCP mentioned that she saw the societal decay: "I see it in the society. Not in the clinic, in the society".

One parent mentioned that there is a lack of awareness of services amongst the youth. In addition there was also negative or inaccurate perception of the services available:

“... they don't think clinic will help them and youth, ah, my [short pause] perception about them they think clinic is for a sick person so you go to the clinic if you're sick and now for them to come here for the service and [short pause] maybe they don't understand that they can get that help. Maybe they aren't so much aware, I think public awareness also about that [pause] they don't consider it. They don't take it seriously to say this service is there and it's helpful".

Support may be from professional networks such as nurses, social workers or teachers. Social support could however be from outside the professional realm and include family or parents as role models who could inspire with positive thoughts, their character, values or goals. This influence could however be positive or negative. A mother commented on the lack of influence:

"there are no role models to teach them or anchor them";
Another mother mentioned the value of having a positive role model:

$$
\begin{aligned}
& \text { "her father taught her these values, this } \\
& \text { helped her". }
\end{aligned}
$$

Parents often don't have the personal resources or time to support the youth. Due to a lack of social support systems, children often needed to rely on themselves:

"I was in a situation where a certain family, ... I could see that the children were actually bringing themselves up, there was nothing wrong with the family except for the trauma, it was a sound family but they were bringing themselves up ... the mother is equally blank, she doesn't know that she is not doing something for these children".

A HCP stated:

"They don't have time. They come home and say 'I am tired...leave me alone"'. Another added: "... Because at home there is no quality time because at home the parents are working, they don't give them support".

One HCP mentioned the influence of the nuclear Westernised family models to possibly explain the lack of family support:

“...Because of westernization we have turned to live as a nuclear family, me my husband and my child. My sister and the other extended family will see to themselves".

An important predictor of youth well-being and resilience is the presence of nurturing adults in a youth's life [9]. Although parents should ideally fulfil this role, the stark realities of loss and displacement may make this an impossible reality. Parents often face their own stressors and trauma that might impede their ability to provide adequate guidance and support. Comments were made [9] that parents (in this case American Indian) may be affected by intergenerational transmission of trauma and loss of traditional parenting practices as a result from forced relocation or removals. The same may hold true for many South African parents who grew up under the apartheid regime where their own parents and role models might have been lacking, thus deprives them of their own role models.

\section{Culminating Effects of Trauma on Communities and Families}

The burden of care often left the HCP feeling of helplessness to affect change:

“... there's not much you can do about it as a clinic sister".

A HCP stated that the helplessness may be so overwhelming that:

"it just creates a chain of frustration that will make you fall down".

In a study into secondary trauma and job burnout of lay counsellors in South Africa compassion fatigue which consisted of secondary trauma and job burnout was found to 
be significantly related [42]. These negative psychological experiences may lead to the delivery of poor quality health services and support to youth who have experienced trauma as well as the community and families.

Parents often felt that":

"the youths' problems become my problems".

A mother states:

"I feel I cannot care for her. At the end it becomes revolving...it is her problem, it becomes my problem which becomes her problem again".

Family members influence and shape each other's behaviour. Parents, especially mothers, may become locked in a cyclic and reciprocal pattern of interaction. Mothers often have a more direct role in child rearing and as such the burden of responsibility often resides with them as they have to manage the child or the family situations [43].

\section{Suggestions for a Holistic Self-Coaching and Leadership Approach}

Participants indicated the need for a holistic approach, and asked for a one stop that could have all youth services in one central place. They recommend a working partnerships and strengthening relationships with social workers from other departments. There should be follow up services as well youth friendly services. Interventions should start at an early age and stage.

\section{Youths'Self-Leadership and Coaching}

It was suggested that youth should be taught to "to fish", be involved when they had problems, and be educated when they experienced peer-pressure. Parents believed that their children should find ways to solve their own problems ("teach them how to fish"). Fathers mentioned the development of independent behaviour by the youth, to move forward after traumatized incidents:

"So that it benefits everyone, so as much as we are saying that the government is not doing anything, we should also look at the positive, the very little thing (cough) that the government is doing, you are right like you said we must encourage the youth, teach a man to fish", and "So that he can also yah, so if these children are taught how to fish then they can live as well not to depend like the money, depending on somebody for food".

A mother believed that children should be involved where there were problems in the family:

"...kids should be part and parcel of, first of all whether its divorce, whether be a parent that passed away or whatever and if necessary to get counselling for them, ahmm I married a man that was much older than me and his youngest daughter was 8 at that stage, her mother had passed away the previous jan and ten years after her mother passed away, another traumatic thing in her life happed and it brought back all these things. We took her to the psychologist who said that apparently, she had phases between the 10 years and she had to cover a whole lot of things, from 8 years old to now a child that was doing honours not a child but a women already that was doing honours .. ahm..ja the sooner I think catch up get counselling get help, I don't know maybe for the child the better and there is a big big... and not only..."

The findings thus indicated the need for youth to influencing themselves to establish a direction and have the self-motivation to stay focused on their direction.

A HCP mentioned that education was needed for the traumatized youth to deal with peer pressure:

"...But once they meet the pressure of peers, they fall".

Peer relationships represent an important component of youth's supportive context. Peer relationships are situated within a complex context with varying aspects influencing these relationships. As such may be supportive or disruptive [44].

\section{Parents Should Take Self-Responsibility}

Self-responsibility is the acknowledgment that a person, through her/his thinking, feeling and behaving, should be in control of how one experience life [45]. HCPs indicated that:

"The parents should take responsibility of teaching these children the rights (pause)...", "that's the programme ..., the parents can develop to take the responsibility of their children" and "youth must learn from their parents".

The importance of parents being equal partners in their children's lives and education has been highlighted in literature [46]. Parents should be provided with information, develop a parental voice and parental school/partnerships should be encouraged.

The need for parenting skills training was pointed out by a HCP:

"...we were wondering how a parenting programme could fit into this thing and if I had an idea what if we included something like parenting skills for the youth so we don't pass on the ignorance about parenting skills to the next generation, that we that's maybe one way we could include that in a programme such as this".

Literature indicates that internationally, successful training centres exist that offer skills training in selfleadership in internal family systems, from beginning to advanced levels [47].

\section{Community Involvement}

The findings indicated that parents should influence themselves in strengthening their social relationships in the communities. 
A mother highlighted the need to strengthen the social fibre of communities:

“... now we keep quiet, I see your child doing whatever he is doing now it's none of my business".

On the other hand a HCP pointed out the need for closer support of community members towards one another:

"And actually they attack each other where they could have supported and helped, I think also what we could also add is, we as nurses, we do not usually see the difference in culture and black and white isn't it neh".

Resilience is not only an innate characteristic. Families can be a resource in itself but also an essential unit of community resilience [7].

The church could play a major role in the life of the youth. A mother stated:

"So I but I think you must empathize the child to go to church, because the church the prayer it does help. She would go to the social worker and they would counsel her but prayer it does help".

Another parent expressed the importance of involvement of the youth in the church:

"Then I, from myself I said you know, I know myself, if I'm angry if I'm emotional the first thing I do I go to church, so I said I'm going to take this girl to church, I went with her to church. Pastor Chris church with this child...so that when she listens to what they are talking and when they counsel her she knows she will never die, when she listens to the person who is preaching I'm telling you she emotionally improved."

The role of religion in the life of the youth was stated by a parent as:

“... so she has made a group of, out of students and she is one of them, so every day during lunch time she would tell them about God about life and the life science teacher at school the life orientation".

The findings therefore indicated that individuals could serve their communities while also strengthening their selfleadership skills.

It became evident that coaching and self-leadership skills started in schools as youth finds support in their school groups.

\section{DISCUSSION}

The findings revealed that the burden of care due to the effects of trauma was empathically felt although it put strain on the system of care at primary health care clinics. Secondary trauma may result due to the situation around traumatized youth, also effecting the helping profession and community who provide formal support. The effect of secondary trauma may surface as health problems, stress, burnout, reduced productivity and capacity for empathy and compassion. This in turn may have an impact on the care that the youth receive from both their family and the community [37]. The health system should thus make major departures from traditional ways of working in being responsive to youth's and parent's needs [48]. Health care professionals should focus on coaching clients in self-assessment of their healthcare needs to better understand their self-responsibility and own leadership behaviours and strengths [49]. Selfassessment is a way to increase self-leadership abilities. As more competencies are achieved, and insight and skills gained, the potential of a positive outcome in health increases.

The findings indicated that traumatized youth have difficulty developing a strong healthy attachment to a caregiver or parent, and that the lack of healthy attachments is linked to youth being more vulnerable to stress. It is stated [50] that the perception of youth is that they have trouble controlling and expressing emotions, and may react violently or inappropriately to situations. Self-leadership needs the ability to develop healthy, supportive relationships with significant others and specifically those kinds of relationships in our families. Youth with a trauma history may have problems in relationships, in friendships, and with authority figures, such as teachers [50]. Self-leadership is related to higher psychological functioning, such as effective coping styles and greater optimism [51]. A youth programme should therefore coach the youth in developing selfleadership skills.

Experiences of participants indicated inadequate resources and infrastructure to support traumatized youth. The barriers impacting on quality follow-up and followthrough care are associated with inadequate service provision related with the availability of resources (human, time, infrastructure); practice system support as well as the attitudes of the health care user and the family [40]. With reference to a leadership programme, coaching is needed to create an awareness of the youth to strive towards more than the status quo towards development. A youth member with no vision equals no leadership. The best leaders are focused on leading change and innovation to keep their circumstances dynamic and growing [52].

Research suggest that nurturing parental practices are positively related to adjustment and relationships and unsafe, unstable and non-nurturing family environments have independent negative effects that can be cumulative [53]. A programme for the youth should focus on an awareness of the challenges around work family life balance, was a hot topic for many decades. A study [54] indicated that the number of hours worked, supervisory support and child difficulties were all predicative of work family life conflict which in turn interfered with work. Breadwinners may have multiple jobs and demands' leaving minimal or no time for involvement in family or community activities [41]. Evidence further suggests that there is a worldwide change in family construction from extended family networks that provide care to nuclear families. There is an increase of oneparent families (unmarried families, divorced families, unmarried mothers) thus putting great strain on the individual family member or parent to provide care and support [55]. This places the focus on coaching the youth 
Table 2. A holistic self-coaching and leadership programme for youth and parents.

\section{Topics}

Managing your own stress; being a nurturing parent and pleasant youth; adapting to a nuclear family; self- direction and creating a vision; a balanced workhome life; developing healthy, supportive relationships, a personal self-leadership development plan, self-responsibility

and their parents in self-leadership by developing a personal self-leadership development plan to translate their vision into reality through planning. As youth spend a lot of time in the school environment, self-leadership strategies can be coached during subjects linked with wellbeing. As assumed in this study, the potential for growth is an inherent part of the human condition and families and communities are active agents of change and support, and should take active responsibility in development of wellness.

\section{CONCLUSION}

In an environment of traumatized youth, leading to secondary stress amongst significant others, coaching by means of youth-parent leadership programme (Table 2) is a strong possibility. The programme can be offered as an after school activity to prepare youth and parents in self-coaching in an environment of financial constraints for appointing professional coachers. This will provide programme attendees access to a sound coaching process that they can follow on their own to become future leaders in their communities.

\section{CONFLICT OF INTEREST}

The authors confirm that this article content has no conflict of interest.

\section{ACKNOWLEDGEMENTS}

This research was a community engagement study funded by the National Research Foundation (CEP20101002000017989) in South Africa.

\section{REFERENCES}

[1] La Greca AM, Boyd BA, Jaycox LH, et al. Children and trauma. Update for mental health professionals. Washington, DC: American Psychological Association 2008.

[2] American Psychological Association (APA). Children and Trauma. Available from: http:/www.apa.org/ pi/families/resources/childrentrauma-update.aspx 2008.

[3] Suffla S, Ratele K, Van Niekerk A. Violence and unintentional injury one of SA's four major health burdens. Available from: https://staff.unisa.ac.za/index.jsp?link=https://staff.unisa.ac.za/econnect/e-news/2014/07/28/violence-and-unintentional-injury-oneof-sas-four-major-health-burdens/ 2014.

[4] Statistics South Africa. National and provincial labour market: Youth. Available from: http://beta2.statssa.gov.za/publications/P02 114.2/P02114.22014.pdf. 2014.

[5] Seedat M, Van Niekerk A, Jewkes R, Suffla S, Ratele K. Violence and injuries in South Africa: prioritising an agenda for prevention. Lancet 2009; 374(9694): 1011-22.

[6] Shavers CA. Exposures to violence and trauma among children and adolescents. Health 2013; 5(2): 298-305.

[7] Landau J. Enhancing resilience: families and communities as agents for change. Fam Process 2007; 46: 351-65.

[8] Seyyedmehdi A, Hossein B. Family and its role in the prevention of social pathologies. Aust J Basic Appl Sci 2011; 5(10): 1324-9.
[9] Goodkind J, LaNoue M, Lee C, Freeland L, Freund R. Involving parents in a community-based, culturally grounded mental health intervention for american youth: parent perspectives, challenges, and results. J Commun Psychol 2012; 40(4): 468-78.

[10] Johnson SB, Pryce JM. Therapeutic mentoring: reducing the impact of trauma for foster youth. Child Welfare 2013; 92(3): 9-25.

[11] Services, D. What are Peer Recovery Support Services? HHS Publication No. (SMA) 09-4454. Available from: http://store. samhsa.gov/shin/content/SMA09-4454/SMA09-4454.pdf 2009.

[12] Ylvisaker M. Self-coaching: a context-sensitive, person-centred approach to social communication after traumatic brain injury. Brain Impairment 2006; 7: 246-58.

[13] Sue-Chan C, Latham G P. The relative effectiveness of external, peer and self-coaches. Appl Psychol 2004; 53(2): 260-78.

[14] Sliter KA, Christiansen ND. Effects of targeted self-coaching on applicant distortion of personality measures, J Personnel Psychol 2012; 11(4): 169-75

[15] Weingarten K. Common shock: Witnessing violence every day: How we are harmed, how. New York: Dutton Press 2003.

[16] Anonymous Self-Leadership Practices. Available from: https:// www.inkling.com/read/organizational-behavior-mcshane-vo nglinow-5th/chapter-6/self-leadership-practices 2011.

[17] Kluft RP, Bloom SL, Kinzie JD. Treating the traumatized patient and victims of violence. In: Bell CC, Ed. Psychiatric Aspects of Violence: Issues in Prevention and Treatment. New Direct Mental Health Serv 2000; 86: 79-102.

[18] Neck CP, Houghton JD. Two decades of self-leadership theory and research: Past developments, present trends, and future possibilities. J Manage Psychol 2006; 21(4): 270-95.

[19] Jooste K, Maritz J. Youths' experience of trauma: Personal transformation through self-leadership and self-coaching. AJPHERD 2014; (in review).

[20] Cooperrider DL, Avital M, Eds. Advances in appreciative inquiry: Constructive discourse and human organizations. Bingley: Emerald 2004.

[21] Brink HI, Van der Walt C, Van Rensburg G. Fundamentals of research methodology for health care professionals. $2^{\text {nd }}$ ed. Lansdowne: Juta 2006.

[22] Burns N, Grove SK. The practice of nursing research: Appraisal, synthesis, and generation of evidence. $6^{\text {th }}$ ed. St. Louis, Missouri: Elsevier 2009.

[23] Reed J. Appreciative inquiry: Research for change. London: Sage 2007.

[24] Cooperrider DL, Sorensen PF, Yeager TF, Whitney D, Eds. Appreciative inquiry: An emerging direction of organization development. Illinois: Stipes 2001.

[25] Landau J. The LINC model: collaborative strategy for community resilience. Sistemas Familiares 2004; 20(3). www.e-libra.com.

[26] Creswell JW. Qualitative Inquiry and research design: Choosing amongst the five approaches. $3^{\text {rd }}$ ed. Los Angeles: Sage 2013.

[27] Mattar S, Vogel EB. The Quality of the Evidence: Qualitative Research in Trauma Psychology. Eur J Psychol 2014; 10(2): 363 75 .

[28] Hennik M, Hutter I, Bailey A. Qualitative research methods. London: Sage 2011.

[29] Krueger RA, Casey MA. Focus groups A practical guide for applied research fourth edition. Los Angeles: Sage Publications Inc 2009.

[30] Lambert SD, Loiselle CG. Combining individual interviews and focus groups to enhance data richness. J Adv Nurs 2008; 62(2): 228-37.

[31] De Vos AS, Strydom H, Fouche CB, Delport CSL. Research at grass roots: For the social sciences and human services professions. $4^{\text {th }}$ ed. Pretoria: Van Schaik 2011.

[32] Guba EG. Criteria for assessing the trustworthiness of naturalistic inquiries. Educ Commun Technol J 1981; 29 (2): 75-91. 
[33] Onwuegbuzie JA, Leech NL, Collins MT. Innovative data collection strategies in qualitative research. Qual Rep 2010; 15: 696-726.

[34] Tolich M. The principle of caveat emptor: confidentiality and informed consent as endemic ethical dilemmas in focus group research. Bioethic Inquiry 2009; 6: 99-108.

[35] Stroul B, Blau G, Friedman R. Updating the system of care concept in philosophy. Available from: Georgetown University Center for Child and Human Development: http://gucchdgeorgetown.net/ data/documents/SOC_Brief2010.pdf 2004.

[36] Whitfield N, Kanter D. Helpers in distress:preventing secondary trauma. Reclaim Child Youth 2014; 22(1):59-61.

[37] Motta RW. Secondary trauma in children and school personnel. J Appl School Psychol 2012; 28 (3): 256-69.

[38] Kounou KB, Bui E, Dassa KS, et al. Childhood trauma, personality disorders symptoms and current major depressive disorder in Togo. Soc Psych Psych Epid 2013; 48: 1095-103.

[39] Hall J, d'Ardenne P, Nsereko J, et al. Mental health practitioners' reflections on psychological work in Uganda: exploring perspectives from different professions. Br J Guid Couns 2014; 42(4): 423-35

[40] Maritz J. Follow-up of mental care users by nurses in the primary care setting in South Africa. J Psychol Afr 2010; 20(1): 61-8.

[41] Van Niekerk A, Seedat M, Kramer S, Suffla S, Bulbulia S, Ismail G. Community, intervention and provider support influences on implementation: reflections from a South African illustration of safety, peace and health promotion. Bio Med Central Public Health 2014; 14(Suppl 2):1-10.

[42] Peltzer K, Matseke G, Louw J. Secondary trauma and job burnout and associated factors among HIV lay counsellors in Nkangala district, South Africa. Br J Guid Couns 2014; 42(4): 410-22.

[43] Saxbe DE, Ramos MR, Timmons AC, Rodriguez AR, Margolin G. A path modeling approach to understanding family conflict: reciprocal patterns of parent coercion and adolescent avoidance. $\mathrm{J}$ Fam Psychol 2014; 28(3): 415-20.

[44] Li Y, Zhang W, Liu J, et al. The role of school engagement in preventing adolescent delinquency and substance use: A survival analysis. J Adolescence 2011; 34(6):1181-92.
[45] Positive-Thinking-Principles. What is responsibility? Available from: http://www.positive-thinking-principles.com/what-is-respons ibility.html 2014.

[46] Kirkbride R. They were a little family': an exploratory study of parental involvement in nurture groups - from a practitioner and parent perspective. Br J Spec Educ 2014; 41(1): 82-104.

[47] The Centre for self-leadership. Training in the Internal Family System Therapy Model. Available from: http://www.selfleadersh ip.org/ifs-therapy-training.html 2014.

[48] Coulter A. Leadership for Patient Engagement [online]. The King's Fund website. Available from: www.kingsfund.org.uk/sites/files/k f/leadership-patient-engagementangela-coulter-leadership-review20 12-paper.pdf 2012.

[49] NHS Leadership Academy. Healthcare Leadership Model self assessment tool. Availabale from: http://www.leadershipacademy. nhs.uk/discover/model-self-assessment-tool/ 2014.

[50] The national Child traumatic Stress Network. Effects of Complex Trauma. Available from http://www.nctsn.org/trauma-types/comple x-trauma/effects-of-complex-trauma 2014.

[51] Dolbier CL, Soderstrom M, Steinhardt MA. The relationships between self-leadership and enhanced psychological, health and work outcomes. J Psychol 2001; 135(5): 469-86.

[52] Myatt M. 12 ways to spot ineffective leadership. Available from: http://www.n2growth.com/blog/6-traits-of-ineffective-leaders/ October 24, 2011

[53] Turner HA, Finkelhor D, Ormrod R, et al. Family context, victimization, and child trauma symptoms: variations in safe, stable, and nurturing relationships during early and middle childhood. Am J Orthopsychol 2012; 82 (2): 209-19.

[54] Brown TJ. Work family conflict among parents of atypically developing children: Exploring the impact of worker, work, and child factors. J Child Family Stud 2014; 23: 854-62.

[55] Georgas J. Family: Variations and changes across cultures. In: Lonner WJ, Dinnel DL, Hayes SA, Sattler DN, Eds. Online readings in psychology and culture. Washington: Center for CrossCultural Research, Western Washington University, Bellingham 2003; p. 13. 